\title{
Materials for Renewable and Sustainable Energy provides the connection between materials, energy, and sustainability
}

\author{
Enrico Traversa $\cdot$ Hicham Idriss
}

Published online: 10 November 2012

(c) The Author(s) 2012. This article is published with open access at Springerlink.com

Looking at the future of humanity, major efforts are devoted to finding pathways for sustainable development. The quality of life is unevenly distributed worldwide with many areas still needing to develop adequate conditions for a dignified life. To this aim, energy is required in far larger amounts than the presently available reserves, which are mostly based on fossil fuels. Energy is the single most valuable resource for human activity and the basis for all human progress. Thus, it is vital to assess and conserve available resources, to consolidate the economical feasibility of under-deployed renewable technologies, and to search for novel methods of energy harvesting, conversion, storage, saving, and use. All should be efficient, renewable and environmentally friendly.

In this framework, while chemistry is the underlying scientific basis, materials are vital in enabling technologies that can offer promising solutions for a sustainable energy future [1]. Most technologies for power supplies that are alternatives to fossil fuel combustion are either too expensive or inefficient, hindering their broad use. These include fuel cells, batteries, supercapacitors, photovoltaics and solar cell devices. Materials with new properties and improved functionalities are needed for boosting the performance and efficiency of the different types of devices, at

E. Traversa $(\bowtie)$

International Research Center for Renewable Energy,

State Key Laboratory of Multiphase Flow in Power Engineering,

Xi'an Jiaotong University, Xi'an, Shaanxi,

People's Republic of China

e-mail: traversa.enrico@gmail.com

H. Idriss

SABIC T\&I (Riyadh) and CRI (KAUST),

Riyadh, Saudi Arabia

e-mail: IdrissH@SABIC.com a lower cost. The same is applicable for deploying solar hydrogen and biofuel production methods, and for introducing new energy-saving technologies, such as in buildings, novel illumination sources for efficient lighting, and thermoelectrics.

Materials for Renewable and Sustainable Energy will offer a new forum for presenting research linking materials, energy, and sustainability. While binary links have been emphasized for "materials and energy [2]" and "materials and sustainability [3]", the intertwining of the different concepts is both necessary and timely. The role of this multidisciplinary journal is to facilitate the dissemination of high-quality scientific results on the material aspects of the deployment of renewable and sustainable energy technologies. The journal covers experimental and theoretical aspects of materials and prototype devices for sustainable energy conversion, storage, and saving, together with materials needed for renewable fuel production. The readers will benefit from the fact that, though different issues need to be solved for the various technologies, very often similar approaches can be borrowed across disciplines. This knowledge exchange will, without doubt, inspire and stimulate endeavours for new discoveries.

Since engineering of the materials nano- and microstructure with their differing associated properties is crucial in improving their performance, close and focused attention is given to advanced materials characterization and testing techniques, such as in situ and in operando methods, and also to materials modelling and computation. In summary, to make renewable energy processes sustainable, considerable efforts are needed at the fundamental, applied and theoretical levels.

Materials for Renewable and Sustainable Energy is an Open Access journal, supported by King Abdulaziz City for Science and Technology, aiming to become the world's 
foremost interdisciplinary forum for publication of research on all aspects of the study of materials for their deployment as vectors for future renewable and sustainable energy pathways. The editors and editorial board are committed in involving and engaging the scientific community in the development and success of this new journal.

Open Access This article is distributed under the terms of the Creative Commons Attribution License which permits any use, distribution, and reproduction in any medium, provided the original author(s) and the source are credited.

\section{References}

1. Chu, S., Majumdar, A.: Opportunities and challenges for a sustainable energy future. Nature 488, 294-303 (2012)

2. Arunachalam, V.S., Fleischer, E.L.: The global energy landscape and materials innovation. MRS Bull. 33, 264-276 (2008)

3. Greene, M.L., Espinal, L., Traversa, E., Amis, E.J.: Materials for sustainable development. MRS Bull. 37, 303-308 (2012)

\section{Author Biographies}

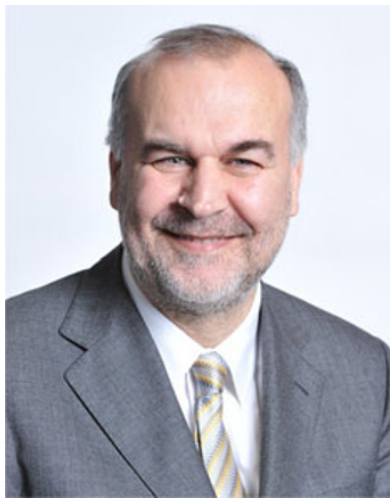

Enrico Traversa in 1986 got his "Laurea" (Italian Doctoral Degree), Summa cum Laude, in Chemical Engineering from the University of Rome La Sapienza. From April 2012, he is the Director of the Department of Fuel Cell Research at the International Center for Renewable Energy, Xi'an Jiaotong University, China. $\mathrm{He}$ joined the University of Rome Tor Vergata in 1988, where he is since 2000 a Professor of Materials Science and Technology. From January 2009 to March 2012, he was a Principal Investigator at the International Research Center for Materials Nanoarchitectonics (MANA) at the National Institute for Materials Science (NIMS), Tsukuba, Japan, leading a unit on Sustainability Materials. His research interests are in nanostructured materials for environment, energy, and healthcare, with special attention to sustainable development. He is an author of more than 500 scientific papers (more than 310 of them published in refereed international journals) and 15 patents. His h-index is 40. Elected in 2007 in the World Academy of Ceramics, in 2011 recipient of the Ross Coffin Purdy Award of the American Ceramic Society for the best paper on ceramics published in 2010. Past Chair of the High Temperature Materials Division of the Electrochemical Society. He is currently an Associate Editor for the Journal of Nanoparticle Research.

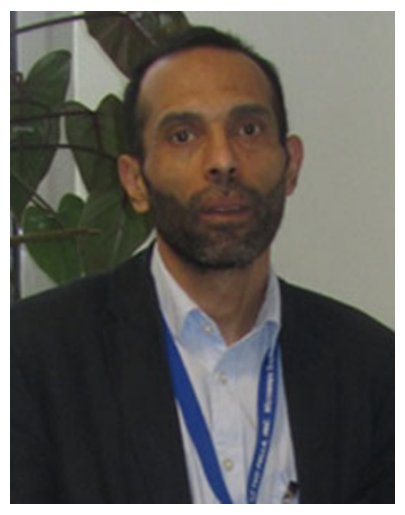

Hicham Idriss has obtained his BSc (1984), MSc (1985), PhD (1987) and habilitation (1997) from the University of Strasbourg (France) and had postdoctoral and research associate positions at the University of Delaware and University of Illinois, Urbana (USA). He joined the Chemistry Department, the University of Auckland (New Zealand) in 1995 as a senior Lecturer then became Associate Professor in 2002. In 2008 he moved to the University of Aberdeen (UK) to become Aberdeen Energy Futures Chair and Professor of Chemistry. In 2011 he moved to SABIC (Riyadh) as Chief Scientist to work on hydrogen production using solar energy. He has over 160 papers and patents. 